\title{
NOTAS SOBRE A MODERNA COMERCIALIZAÇÃO DE ALIMENTOS NA EUROPA: O CASO DA FUNDAÇÃO MAX HAVELAAR.
}

\author{
Marco Mitidiero*
}

\section{RESUMO:}

O presente texto é resultado de uma pré-pesquisa a respeito da comercialização de alimentos "alternativos" (ecologicamente corretos) no mercado europeu. Os relatos e as reflexões desenvolvidas atentam para novas formas de produção, comercialização e consumo impulsionados por organizações de mediação e apoiadas por parte da sociedade civil, visando a negar as formas tradicionais de comércio dominadas pela ação das multinacionais. O estudo da formação da marca holandesa Max Havelaar será apresentada neste texto.

PALAVRAS-CHAVE:

Organizações de mediação, alimentos ecologicamente corretos, Fundação Max Havelaar.

\section{ABSTRACT:}

The present text is a result of a pre-research regarding the commercialization of "alternative" foods (ecologically corrects) in the European trade market. The stories and reflections developed attempt to new ways of production, commercialization and consumption stimulated by entities of mediation and supported by part of the society, aiming to deny the traditional trade shapes, in which the multinational companies detain the control. This text presents the study about the creation of the dutch label Max Havelaar.

\section{KEY WORDS:}

Organization of mediation, ecologically correct foods, Max Havelaar Foundation

\section{Introdução}

A título de nota introdutória vale reconhecer que as grandes multinacionais do setor alimentício dominam a produção, a distribuição e a comercialização dos alimentos em todo o mundo. Colossais empresas como a Nestlé, Coca-Cola, Parmalat, Unilever, Asgrow, Monsanto, Novartis, Sandoz, Ciba Geigy, Cargill, Pioneer, Hoechst, Beatrice Foods, Boeing Aircraft, J. R. Reynolds, Tenneco, American Brands, Getty Oil, Consolidated Foods, Ralston Purina, Central Soya, Castle \& Cooke, Seagram's, Hershey Foods, Gulf \& Western, Del Monte e United Fruit Company monopolizam a circulação dos alimentos produzidos nos cinco continentes ${ }^{1}$.
Grandes empresas do setor industrial e petrolífero (Colgate Palmolive, Royal DutchShell, Exxon, British Petrolium) que, em tese, não teriam nenhuma relação com a produção de alimentos, passam a realizar significativos investimentos no setor agrícola, principalmente na produção e monopólio das sementes. Assim, a concentração de todas as etapas da produção agrícola na escala internacional - da produção de sementes à venda das mercadorias - em poder de poucas multinacionais nos aponta um panorama de dominação, coerção, monopólio e poder político e econômico que deixam a sociedade civil e a administração pública à mercê destas grandes empresas ${ }^{2}$.

* Mestre e doutorando em Geografia Humana pela Universidade de São Paulo, Professor Substituto do Departamento de Geociências da Universidade Federal da Paraíba (UFPB). E-mail: mitidierousp@yahoo.com.br 
Conglomerados como a United Fruit Company constituem verdadeiros impérios econômicos que condicionam a organização territorial e dominam economicamente países inteiros. O exemplo mais visível do poder desta empresa está na paisagem da América Central. Nesta região, a United Fruit Company possui 1 milhão de hectares, no qual emprega $100 \mathrm{mil}$ assalariados rurais e mantém relações comerciais para a compra da produção agrícola com mais de 1 milhão de pequenos proprietários rurais (camponeses). E a rede de dominação vai mais adiante: além de controlar as economias locais, esta empresa é proprietária de $3 \mathrm{mil}$ quilômetros de ferrovias, portos, frotas de navios, terrenos de reserva (não cultivados), sistemas de comunicação locais e etc. (Fórmica, 2002, p. 33).

A territorialização da Gulf \& Western na República Dominicana, a partir da atividade agrícola, indica a dominação de outros ramos da economia. Além dos 1.200.000 hectares de plantações (principalmente de cana de açúcar), das ferrovias que alcançam todas as regiões de produção agrícola da empresa, do controle do sistema portuário, esta empresa é proprietária das indústrias de materiais para a construção e dita as normas para a exploração deste território pela atividade turística (Fórmica, 2002, p. 45).

Outra dimensão do domínio exercido por estas multinacionais, tanto nos seus países de origem (desenvolvidos) como nos países estrangeiros (subdesenvolvidos), está no controle dos sistemas políticos. Investimentos maciços em campanhas políticas, indicações de representantes na administração pública (ministros, deputados, governadores, senadores, presidentes) e um eficiente sistema de lobby nos poros governamentais transformam estas multinacionais em entes decisórios da vida econômica, social e política das sociedades.

Um tema agravante desta realidade é que estas multinacionais foram, e continuam sendo, responsáveis pela destruição do meio ambiente e pela exploração da mão-de-obra assalariada e camponesa. A exaustiva utilização de maquinários, agrotóxicos e fertilizantes químicos que agridem a natureza também agride os seres humanos. A Organização Mundial de Saúde aponta quantidades significativas de graves doenças causadas pelo consumo de alimentos produzidos à base de agrotóxicos e fertilizantes químicos, e a Organização Mundial do Trabalho, há décadas, mostra o baixo nível de renda dos assalariados rurais e camponeses relacionados a estas empresas multinacionais.

Diante desta realidade começam a surgir com mais força e intensidade formas alternativas de produção e comercialização dos alimentos. Organizações Não-Governamentais, entidades assistenciais, associações, cooperativas de produtores e consumidores e uma pequena parte da sociedade civil mundial tomam partido na direção de transformar a produção e o comércio de alimentos em uma atividade econômica mais justa, solidária e "limpa" (ecologicamente sustentável).

A idéia da produção agrícola não destruidora da natureza, que tomou impulso na década de 80 , não mais se restringe à produção de um alimento ecologicamente correto (orgânico), sem a utilização dos produtos químicos e sem agredir o meio ambiente, mas também se preocupa com todas as etapas do processo produtivo. Por exemplo, a produção de alimento sem agrotóxico agora passa a ser incentivada não só do ponto de vista dos consumidores e da natureza a ser preservada, mas das condições de vida dos próprios produtores. A garantia de uma renda justa ao produtor e de um sistema assistencial (saúde, educação, transporte, moradia, etc.) aparecem nas pautas de reivindicações não só dos movimentos ambientalistas como das próprias cooperativas de produtores e consumidores ${ }^{3}$.

É desta face moderna e ainda muito restrita da produção, distribuição e consumo de alimentos que irei levantar algumas reflexões nas notas a seguir. 


\section{I - A Importância das Organizações de Mediação}

Intitular as associações civis que lutam por formas de comercialização de alimentos mais justas, solidárias e ecologicamente corretas de organizações de mediação tem por objetivo abarcar uma multiplicidade de iniciativas levadas a cabo por diversos setores da sociedade civil. São movimentos sociais, sindicatos, ONG's, institutos de pesquisa, universidades, cooperativas e associações que produzem manifestações em prol de transformações nas formas de produção alimentar ${ }^{4}$.

O episódio da "vaca louca" na Inglaterra inverteu o longo processo de aumento do consumo de carne bovina que vinha ocorrendo na Europa pós 2a Guerra Mundial. Além da conscientização do consumidor europeu a respeito da grande quantidade de gordura presente na carne bovina e suína e dos altos preços pagos por estes produtos, a doença da vaca louca apareceu como uma grande ameaça à sanidade da alimentação dos consumidores, o que levou as organizações de mediação a pressionar o Estado a incentivar outras formas, estas mais limpas e responsáveis, de criação animal. Com isso, países como a França e a Itália estão consumindo cada vez mais frango e peixe, embora o consumo de carne bovina e suína continue sendo maior no mercado de proteína animal.

A participação da sociedade européia nas decisões políticas por meio das manifestações coletivas e da gênese de organizações de mediação, por mais ínfimas que sejam, alcançam algumas estruturas da administração pública. O grito de "não ao alimento sujo" soa por toda a Europa.

O papel das organizações de mediação no campo do comércio de alimentos vai muito além da mediação entre sociedade e Estado, mas funda, ou melhor, refunda uma cadeia que liga e media as relações entre as duas pontas do mercado de alimentos, dos produtores aos consumidores. Esta mediação tem o objetivo de trazer um alimento totalmente saudável ao consumidor, remunerando de forma justa o produtor.

Como estas organizações de mediação são formadas no seio da sociedade e não pelo Estado ou pela iniciativa privada (multinacionais), a sua ação histórica caminha no sentido de garantir maior responsabilidade na produção de alimentos. Mas estas ações passaram a dar passos mais rápidos e mais ambiciosos diante das questões latentes. Os agentes de mediação começam a trabalhar na direção de mediar a própria cadeia de circulação dos produtos alimentícios: da produção ao consumo, ou seja, o fator principal da existência de algumas destas organizações não está baseado nas ações de caráter estrito de reivindicação política para a proteção do meio ambiente frente ao Estado e instituições privadas, mas sim de constituir empresas, fundações e cooperativas que propõem e realizam novas formas de produção e comercialização agrícola.

As experiências desenvolvidas por organizações como a Fundação Max Havelaar são reveladoras desta nova face da participação da sociedade civil nas decisões de seu cotidiano.

O padre holandês, radicado no México, Frans van der Hoff e o historiador e teólogo holandês Nico Roozen, preocupados com o problema da fome e com a exploração dos camponeses do Terceiro Mundo, idealizaram uma organização que teria como função principal sustentar a produção de alimentos ecológica e socialmente corretos e comercializar estas mercadorias sob o signo de uma marca própria, formada pelos próprios produtores e apoiada pelos consumidores. Assim, surgiu a marca Max Havelaar, nome do protagonista principal de um romance holandês escrito por Multatuli que se tornou símbolo da resistência indonesiana contra o imperialismo holandês.

A principal proposição desta organização era a de mudar as tradicionais formas de relações comerciais entre os países ricos e os países pobres e para isso, partiram da seguinte premissa: não acreditar nos grandes e extensos 
programas de ajuda humanitária e nos tradicionais programas de doação de alimentos gerados por importantes organismos internacionais como o Banco Mundial e a Organização das Nações Unidas.

Segundo esta fundação (Roozen e Hoff, 2003, p. 10/11) os sistemas de doações de alimentos criam uma falsa e injusta economia, destruindo a dinâmica social dos países pobres ${ }^{5}$.

O depoimento colhido, em 1980, por Frans van der Hoff de camponeses plantadores de café no sul do México foi sintomático para a articulação de novas propostas. Segundo o camponês Isaías Martins: "Não queremos ser ajudados, não estamos na mendicância. Se vocês pagassem um preço razoável pelo nosso café, poderíamos viver tranqüilamente sem ajuda." ${ }^{6}$ (Roozen e Hoff, 2003, p. 10)

Assim, o mote principal desta organização fundada no final da década de 80 era o de pagar preços mais altos (justos) aos camponeses do Terceiro Mundo. Mas cabia aos idealizadores desta proposta encontrar a melhor forma de realizá-la. A idéia seria produzir diversas manifestações frente às grandes multinacionais do setor alimentício? Ou pressionar o Estado na formulação de leis que garantissem justiça aos produtores de alimentos?

Um terceiro caminho foi gerado quando Roozen e Holff resolveram lançar uma marca comercial própria no livre mercado de alimentos. Frente a frente com as multinacionais e grandes empresas nacionais do setor alimentício, a marca Max Havelaar foi lançada com o objetivo de disponibilizar ao consumidor alimentos ecologicamente corretos e socialmente justos e solidários com os produtores. Não se tratava de vender um produto de qualidade mediana apelando para o discurso de "ajudem os latinos americanos", mas, sim, de um produto de qualidade superior comparado aos produtos comercializados pelas grandes empresas, e com - caráter essencial de valorização dos produtores $^{7}$. Estes produtos devem seguir a seguinte pirâmide de prioridades:

\section{Qualidade Social \\ Qualidade Ecológica \\ Qualidade do Produto \\ Segurança do Produto \\ Disponibilidade do Produto}

A Fundação Max Havelaar teve um grande impulso na segunda metade da década de 90. Após vencer batalhas comerciais com a gigante holandesa no setor de processamento e distribuição de café "Douwe Egberts", a marca Max Havelaar expandiu seu raio de ação por nove países da Europa e acolheu como marca própria outros tipos de produtos: chá, banana, cacau, achocolatado e calças jeans.

Todos os produtos comercializados com esta marca são provenientes de países da América Central, da América do Sul e da África. A relação da marca Max Havelaar com os camponeses produtores ultrapassa a noção de mediação na medida em que estes camponeses, organizados em cooperativas, assumem o signo da marca como próprio e passam a participar das decisões da fundação.

Alguns números significativos da dimensão que atingiu os produtos Max Havelaar no mercado internacional indicam o sucesso, ainda modesto, desta iniciativa: por exemplo, a fundação já é responsável por $4 \%$ do mercado de café na Holanda, $5 \%$ na Inglaterra e $8 \%$ na Suíça; a respeito do mercado de banana, 20\% do mercado suíço é comandado pela marca Max Havelaar (TransFair) e entre 4 e $6 \%$ na Itália, Holanda e Inglaterra. Isso só foi possível quando a política desta fundação foi direcionada no sentido de comercializar estes produtos nas grandes cadeias de distribuição (supermercados e hipermercados) e não centralizar a venda apenas em nichos alternativos como casas especializadas em produtos orgânicos ou em feiras livres de produtos ecológicos.

O produto alternativo para o consumidor alternativo em lugares alternativos, transformou-se em produto comum para o consumidor comum distribuídos nas comuns 
Notas sobre a moderna comercialização de alimentos na Europa:

gôndolas dos hipermercados. Basta o consumidor escolher?

\section{II - O Consumidor Crítico}

Após alguns anos de experiências, os idealizadores da marca Max Havelaar concluíram que o preço mais alto pago ao produtor não era a única solução, e que o problema principal era vender estes alimentos em larga escala, já que não produziriam transformações efetivas se o produtor vendesse apenas $10 \%$ da sua produção a preço justo e $90 \%$ a preço baixo. Toda a produção deveria ser comercializada a um preço que garantisse ao agricultor condições mínimas de sobrevivência.

Não só a fundação Max Havelaar como outras organizações de mediação européias investem em manifestações, campanhas publicitárias, palestras, congressos e exposições com a intenção de conscientizar os consumidores. Fundar um novo modelo de consumo é o objetivo destas organizações.

Este novo modelo de consumo deve ser impulsionado com a formação e conscientização de um mercado consumidor crítico, no qual o comprador tenha a possibilidade e a capacidade de discernir os produtos do ponto de vista da sua qualidade e da sua proveniência.

Freqüentemente os consumidores que adquirem produtos ecologicamente corretos e socialmente justos fazem parte de uma pequena parte da população com caráter muito sensível e politizado a respeito das questões que envolvem a produção dos alimentos consumidos por eles e por toda a sociedade. Antes de comprar, eles procuram e exigem informações sobre a qualidade e a gênese do produto. O ato de comprar é pautado pela preocupação com a própria vida e com a vida dos produtores.

Manuais organizados por estes agentes de mediação, e publicados por editoras comprometidas com esta causa, reúnem uma gama de informações sobre as multinacionais do setor de alimentos. Informações sobre sanidade dos produtos, preservação do meio ambiente, remuneração dos agricultores associados e remuneração dos trabalhadores assalariados explicitam a realidade interna de determinadas empresas e a história do produto $^{8}$.

Por isso, o boicote às empresas poluidoras do meio ambiente e exploradoras de mão-de-obra barata deixou de constituir fatos isolados e momentâneos, semelhante a uma greve dos consumidores contra os produtos de determinada empresa, transformando-se em uma atitude cotidiana. "Os consumidores éticos custam caro às grandes multinacionais", esta é a conclusão de quatro anos de pesquisas encomendadas pelo Banco Cooperativo Britânico e pelas fundações New Economics Foundation e Future Fundations. Grandes multinacionais como Esso e Nestlé perdem o total de 3,6 bilhões de euros ao ano somente na Inglaterra ${ }^{9}$.

Esta pesquisa mostra que na Inglaterra, entre 1999 e 2002, o mercado dos produtos considerados éticos cresceu $44 \%$, enquanto os rendimentos das empresas que os comercializam passaram de 6,7 para 9,6 bilhões de euros.

Outros dados e informações coletadas por esta pesquisa são:

- as escolhas por produtos éticos não se restringem apenas aos alimentos, mas também atingem os serviços bancários e financeiros;

- 52\% dos britânicos procuram evitar a aquisição dos produtos das grandes multinacionais concebidos como produtos "discutíveis";

- a maioria dos britânicos prefere realizar as suas compras em pequenos negócios na vizinhança com a intenção de sustentar a própria comunidade;

- 2,5 bilhões de euros foram gastos em produtos orgânicos no ano de 2002;

- $40 \%$ dos ovos comercializados eram provenientes de pequenas empresas locais. 
A pesquisa indica ainda que estas cifras estão colocando as multinacionais em alarme devido à conclusão do estudo indicar que estas transformações no consumo representam e expressam "valores profundos" do caráter do consumidor e não iniciativas espontâneas e esporádicas.

Consumidores críticos começam a exigir das empresas a exposição de "etiquetas claras" nos produtos comercializados. Isto é, o ato da compra é decidido após a leitura das informações presentes nas embalagens dos produtos. Nelas deve estar presente uma espécie de histórico do produto, contendo, além das informações sobre valor nutricional e data de validade, informações sobre a origem do alimento, a certificação no caso de alimentos orgânicos e selos ou signos indicando que a empresa não polui o meio ambiente. Segundo o economista italiano Roberto Fanfani (2000, p. 123), "o princípio da precaução efetivou-se em toda a Europa e pode ser uma linha a seguir para afrontar corretamente o problema dos alimentos geneticamente modificados (transgênicos) e, de forma mais geral, a segurança alimentar da população. Os problemas da correta informação alimentar nas embalagens e nas informações sobre a origem do alimento tornam-se relevantes não só pela preocupação com a saúde dos consumidores, mas também para a valorização dos produtos típicos, de qualidade e de origem controlada."10

No caso da marca Max Havelaar, a fundação trabalhou no sentido de criar novas formas de comunicação entre os consumidores e os produtores. Quando esta marca é lançada na Holanda e começa a conquistar espaço, passa a reorganizar parte do mercado de alimentos e a ditar novas regras ${ }^{11}$. Por exemplo, a comercialização de café justo e solidário pela fundação Max Havelaar retirou do anonimato alguns atores do mercado: "a oferta provém dos cultivadores de café, identificados com nome e sobrenome, e fazem parte da cooperativa de produtores da Fundação Max Havelaar". Por outro lado, "as questões partem dos consumidores: queremos beber um bom café e conhecer a sua proveniência, o método produtivo deve ser socialmente e ecologicamente sustentável. Agora o consumidor também possui rosto e emerge do anonimato..." (Roozen e Hoff, 2003, p. 36)

A importante rede de supermercados italiana Coop é um exemplo significativo na transformação dos anônimos consumidores em atores do mercado. A Coop é uma rede de comercialização de alimentos fundada pela sociedade civil organizada em forma de cooperativa. Esta cooperativa espacializada em toda a Itália privilegia a comercialização de alimentos ecologicamente corretos e garante preços não abusivos aos consumidores.

Fanfani (2000, p. 129), entusiasmado com estas novas organizações, afirma que a agricultura moderna inaugura novas relações entre os produtores agrícolas e os consumidores, nas quais garantem a renda e a reprodução (profissionalização) do agricultor e, ao mesmo tempo, asseguram alimentos saudáveis aos consumidores.

Esta nova relação entre produtor e consumidor existente em toda a Europa ainda atinge pequenos setores da população e depende diretamente do desenvolvimento de dois fenômenos: da existência das organizações de mediação que possibilitam a chegada destes alimentos à Europa e da educação e politização da população em geral.

\section{III- A Distribuição dos Alimentos}

Entre a plantação e o consumo e entre o agricultor e o consumidor existe uma complexa cadeia comercial de distribuição da produção. São as flutuações dos preços, os impostos ou subsídios governamentais, as tarifas alfandegárias, os meios de transporte (caminhões, trens, navios e aviões), a estrutura do transporte (estradas, ferrovias, portos, rotas aéreas), a estocagem, o processamento (industrialização) da mercadoria, a concorrência no mercado, a especulação no mercado de futuros das bolsas de valores, a necessidade 
de estratégias de marketing, as políticas agrícolas dos Estados, etc., alguns ítens de extrema importância que determinam as duas pontas da cadeia de alimentos, da produção ao consumo.

Outro ponto importante é a modernização dos sistemas distributivos. Com o avanço nos estudos de logística e transporte o comércio internacional de alimentos possibilita novos intercâmbios, garantindo ao consumidor produtos frescos e não deteriorados vindos de outros continentes. Este moderno sistema distributivo permite que alimentos antes extraordinários nas gôndolas dos mercados e feiras tornem-se cada vez mais freqüentes.

A partir deste contexto, qualquer iniciativa de produção, distribuição e comercialização de alimentos que tenha como objetivo principal tornar o comércio mais justo e solidário terá que afrontar estas características que norteiam a cadeia de distribuição de alimentos.

Como a proposta da Fundação Max Havelaar era a de lançar uma marca comercial própria no mercado e não criar uma marca de certificação dos produtos orgânicos, eles foram obrigados a desenvolver diversas estratégias de distribuição e comércio de seus produtos frente ao mercado e seus ditames. Isto quer dizer que os produtos Max Havelaar não estavam fora de todas as características determinantes do mercado global. Certamente se entrassem no mercado apenas como comercializadores de produtos alternativos em pequena escala, seriam destruídos pelo próprio mercado de alimentos comandado pelas grandes multinacionais ou permaneceriam na condição de "alternativos", concentrados em pequenos e quase insignificantes nichos comerciais.

O primeiro passo dado pela fundação no sentido de afrontar os perigos do mercado foi a eliminação da antiga figura do atravessador ${ }^{12}$, vendendo os produtos diretamente para os consumidores ou indústrias de processamento (agroindústrias).
Para que os produtos fossem comercializados em larga escala na Europa foram utilizados os modernos métodos logísticos de distribuição, os mesmos utilizados pelas multinacionais, e foi travada uma batalha com os grandes supermercados e hipermercados para que estes comercializassem os produtos Max Havelaar ${ }^{13}$. Negociar com as administrações dos portos, com proprietários de navios e com os gerentes comerciais dos hipermercados fazia e faz parte da agenda dos quadros da Fundação Max Havelaar.

O terceiro passo na promoção e defesa desta marca foi controlar o preço dos produtos comercializados e divulgá-los a toda sociedade. Embora a eliminação do intermediário barateie - preço da mercadoria, a produção ecologicamente correta traz outros encargos financeiros à produção, como por exemplo, a não utilização de agrotóxicos ou outros produtos químicos que muitas vezes acabam baixando o rendimento da produção em termos quantitativos. Isto geralmente faz com que o preço do alimento orgânico e socialmente correto atinja um patamar um pouco mais elevado comparado aos preços dos produtos normais (convencionais) ${ }^{14}$. Cabe aos consumidores pagar preços um pouco mais altos por estes produtos. Para isso, a fundação Max Havelaar desenvolveu estratégias de marketing em que, a um só tempo, divulgava os produtos ecologica e socialmente corretos e justificava os preços mais altos pagos pelo consumidor.

Por outro lado, os eficientes planejamentos logísticos na distribuição dos alimentos utilizados pelas multinacionais do setor passaram a ser armas da marca Max Havelaar no barateamento da mercadoria. A comercialização da banana e de calças jeans desta marca já atinge os preços médios no mercado geral de comercialização destas mercadorias. 


\section{IV - A Produção e os Produtores}

Carmelo Fórmica (2002, p. 260), ao discutir as etapas da cadeia de distribuição de alimentos na Europa, afirma que "a remuneração do produtor representa uma pequena fração do custo final do produto e a maior parte dos rendimentos acabam concentrados nas mãos de um número restrito de beneficiários"15.

Por mais que a política agrícola da União Européia garanta a formação de preços mínimos para os agricultores, todo o processo posterior à colheita torna o preço da mercadoria muito mais elevado do que o preço pago ao produtor. Do transporte à industrialização do alimento, da embalagem à publicidade da mercadoria, o preço pode sofrer várias multiplicações. Quando a discrepância dos preços é muito grande, dependendo das épocas de colheita e das flutuações de preços no mercado, a União Européia garante também a renda mínima ao agricultor, ou seja, se a renda adquirida com a venda da colheita não é suficiente, os governos disponibilizam diretamente um salário de apoio ao agricultor.

Mas como este processo ocorre no mercado internacional de alimentos e, principalmente, em relação à exportação de produtos pelos países pobres?

Os idealizadores da Fundação Max Havelaar partiram da problematização deste processo como norteador das iniciativas e projetos futuros. A constatação da subordinação das famílias camponesas produtoras de café no México em relação aos atravessadores, comerciantes e multinacionais, serviu para mapear um quadro geral dos meandros que as relações entre produtores e empresas reservam aos agricultores.

Muito freqüentemente, a relação entre os camponeses e as multinacionais é efetivada por intermediários locais. Estes determinam as culturas a serem cultivadas (dadas as exigências do mercado), antecipam as sementes, fazem a assistência técnica, disponibilizam fertilizantes, herbicidas, produtos químicos em geral e os instrumentos de trabalho e fazem o transporte da colheita. Tudo isso se caracteriza como uma forma de empréstimo ao camponês, cabendo a ele pagar o intermediário no momento da colheita.

A multinacional fixa o preço do produto com o intermediário e deixa-o livre para estabelecer um outro preço com o produtor. Obviamente, o preço estabelecido nesta relação está abaixo do preço médio do produto. Esta é a forma mais comum nas relações comerciais entre pequenos produtores dos países pobres e multinacionais do setor.

A idéia central do comércio justo e solidário é a de pagar preços mais altos a estes camponeses sem causar um aumento insustentável do custo da mercadoria nos lugares de distribuição, contrariando a regra geral do comércio internacional que é a da subordinação e exploração dos camponeses e produtores. Como já descrevi, a eliminação dos atravessadores, a utilização de métodos modernos nas áreas de logística e transporte e a conscientização dos consumidores são estratégias adotadas com a finalidade de tornar estes produtos vendáveis nas grandes redes de distribuição.

Além de pagar preços justos aos produtores, a Fundação Max Havelaar gerou outra alternativa: o pagamento antecipado pela mercadoria, no qual $60 \%$ da colheita prevista são pagos antecipadamente e $40 \%$ após as transações comerciais. Esta experiência mostrou que é mais importante capitalizar o agricultor em diversos períodos da produção do que pagar um preço um pouco mais alto no final do ciclo produtivo. No caso do comércio de banana, produzida por grandes proprietários rurais à base de mão-de-obra assalariada, o produtor teve que aceitar todas as exigências ecológicas e sociais da Fundação Max Havelaar. Esta fundação incentivou a formação de sindicatos autônomos pelos trabalhadores rurais assalariados que regulassem o processo produtivo da banana. 
A justa capitalização dos camponeses permitiu o pagamento de dívidas bancárias e comerciais antigas e elevou o nível de vida destes sujeitos, e a existência de um sindicato sólido e orgânico possibilitou que os trabalhadores regulassem os níveis da exploração de seu trabalho.

Assim, a Fundação Max Havelaar registra significativas transformações na qualidade de vida dos produtores, principalmente na América Central, na medida em que estes disponibilizam alimentos saudáveis aos mercados consumidores.

\section{V- O Papel do Estado}

A União Européia é, atualmente, a principal área comercial de produtos agrícolas em nível mundial devido a sua posição dominante como exportadora e importadora de produtos agrícolas. Não é por acaso que a Política Agrícola Comunitária (Pac) constitui o principal setor de intervento da e na União Européia.

Esta política agrícola, caracterizada como mantenedora dos preços mínimos para os produtores e a dura proteção às importações vêm sofrendo modificações significativas desde a segunda metade da década de 80 . Desde 1986 a União Européia é alvo de intensas pressões políticas na Organização Mundial de Comércio (OMC) pelos países exportadores de alimentos, principalmente os Estados Unidos.

Na década de 90 a União Européia aceita diminuir os subsídios aos produtores, mas passa a centrar estes subsídios na produção agroambiental, na política de desenvolvimento rural, de conservação da paisagem, de proteção do meio ambiente, de valorização do patrimônio cultural e revitalização das regiões rurais. Estas ações ficaram conhecidas como o "papel multifuncional" do Estado na gestão do espaço rural europeu. A respeito da histórica proteção ao agricultor, esta política passou a dar mais ênfase à política de indenização dos produtores, sustentando diretamente a renda destes sujeitos em detrimento da garantia do preço mínimo. Este processo vem indicando uma redução progressiva da proteção à produção agropecuária européia ${ }^{16}$.

Todo este processo é alvo de críticas e produz uma efervescência de propostas alternativas levantadas por instituições, ONG's e movimentos sociais que lutam pelo comércio justo e solidário. Geralmente todas estas manifestações e reivindicações culminam em uma crítica direta e severa aos efeitos da globalização.

A Fundação Max Havelaar adotou um discurso que parte do princípio de valorizar o intervento do Estado como essencial para a obtenção de uma economia justa e solidária, contrariando os mandamentos do neoliberalismo. Assim, o Estado teria a função de formar um cidadão crítico (investimento na educação), garantir um regime democrático e criar um quadro legislativo que direcione para a produção sustentável ${ }^{17}$.

Neste sentido, as relações internacionais no comércio de alimentos, principalmente entre os países ricos e países pobres, estariam pautadas por uma política de bom senso. Isto é, ao mesmo tempo em que o Estado deve intervir garantindo o sustento da sua população rural ele deve incentivar o comércio internacional com os países pobres, defendendo a remuneração justa dos produtores e a proteção do meio ambiente.

É claro que isto se constitui em questões complexas que envolvem a soberania dos países envolvidos e a existência das políticas agrícolas de cada nação. Neste caso, as propostas geradas pela Fundação Max Havelaar e por demais organizações de mediação indicam a necessidade da formação de um corpo legislativo internacional que regule a ação das multinacionais nos países pobres.

A situação atual assemelha-se a um "apartheid econômico e jurídico", no qual governos e Organização Mundial de Comércio (OMC) são comandados pelas grandes 
multinacionais. Mesmo com este contexto, as organizações de mediação vêm mostrando e indicando possíveis transformações na estrutura e na forma do comércio internacional.

\section{Considerações Finais}

Dados da revista Globo Rural (maio/ 2004) mostram que a agricultura orgânica movimentou no mercado mundial, em 2004, uma cifra de 23 bilhões de dólares e que a atividade tornou-se a nova área de investimentos dos agronegócios ou agrobusiness em diversos países.

O problema deste novo quadro do comércio internacional é que a agricultura ecologicamente correta não está diretamente ligada a realização do comércio justo e solidário. Isto quer dizer, principalmente, que a produção dos alimentos orgânicos pelas grandes empresas não respeita as exigências sociais necessárias para a proteção do meio ambiente, ou melhor, do ambiente inteiro.

Naomi Klein ${ }^{18}$ afirma que o capitalismo absorve esta idéia e a torna inofensiva. O desenvolvimento dos produtos biológicos, justos e solidários limita-se a despolitizar o problema. $\mathrm{Na}$ medida em que as grandes empresas obtém os segmentos do mercado, a situação de exploração da mão-de-obra e o desrespeito aos países pobres continuam.

Outro problema, indicativo deste processo de subordinação das iniciativas geradas como alternativas à produção capitalista dirigida pelas grandes empresas, materializa-se na existência cada vez maior de organizações de mediação com objetivos duvidosos e ligados às multinacionais. O mesmo processo ocorre com algumas agências de certificação nacional ou internacional e com algumas centrais sindicais de trabalhadores.

Estas são questões que devem ser debatidas e combatidas pelas organizações de mediação, pelos Estados e pela sociedade civil. A Fundação Max Havelaar conseguiu indicar um processo dentre outros possíveis na transformação da produção, distribuição e consumo de alimentos. A fala do camponês produtor de café no sul do México, após comungar da experiência de gerir uma marca própria, organizada pelos próprios produtores, é significativa deste processo: "Depois do nascimento da Fundação Max Havelaar nós, agricultores índios, continuamos pobres, embora verificamos melhoras na nossa condição de vida. Mas a contribuição mais importante da fundação é a de ter restituído nossa dignidade humana. Não vivemos mais subordinados aqueles poderes econômicos anônimos que nos humilhavam". (Roozen e Hoff, 2002, p. 93/94)

\section{Notas}

1 Em alguns casos monopolizam toda a cadeia produtiva e até definem padrões técnicos de uso da terra, das práticas agrícolas e das formas de trabalho.

2 É evidente que a relação entre Estado e iniciativa privada aproxima-se mais da dependência mútua do que da independência ou autonomia. Neste caso, as grandes empresas que produzem e comercializam alimentos dependem do apoio estatal (subsídios, regalias fiscais e tributárias, infraestrutura, etc.) para desenvolvimento dos seus negócios e o Estado depende dos impostos coletados com a produção e comercialização da produção. Porém, estas empresas constituem grandes monopólios, nas quais adquirindo poderes que colocam os governos e suas políticas na subserivência dos gostos e decisões destas empresas monopolistas.

3 O mote central da "ideologia" que se formou entorno da produção de alimentos orgânicos e, 
principalmente, a formação do mercado para estes produtos a partir de campanhas publicitárias de "conscientização", frisava a figura do homemconsumidor e por conseguinte da preservação da natureza. Muito pouco perguntava-se: quem produz estes alimentos?

${ }^{4}$ Muitas vezes o Estado também age de forma subserviente às manifestações coletivas destes sujeitos, como na atualização da legislação ambiental da Inglaterra e da França a partir da reivindicação da sociedade civil.

${ }^{5}$ A Fundação Max Havelaar deixa claro que a crítica aos sistemas de doações não diz respeito a manifestações pessoais ou de alguns grupos na disponibilização de alimentos aos países que convivem com o problema da fome, mas a projetos dos imensos fundos financeiros utilizados para a cooperação ao desenvolvimento e às políticas governamentais destes países.

6 Tradução realizada pelo autor.

${ }^{7}$ As empresas e instituições que emitem certificados a produtos ecologicamente corretos (biológicos e orgânicos), a partir das experiências geradas por diversas organizações de mediação como a Fundação Max Havelaar, passaram a adotar critérios sociais, e não só biológicos, na emissão das certificações. Em toda a Europa existe uma corrente impulsionada pelas multinacionais que pressionam as instituições responsáveis pela certificação no sentido de desqualificar os critérios que garantem a comercialização socialmente justa.

8 Freqüentemente, pude encontrar consumidores munidos destes manuais no momento das compras nos supermercados italianos.

9 Pesquisa publicada pelo Jornal City Firenze (Florença/Itália) no dia 10 de dezembro de 2003.

10 Tradução realizada pelo autor.

${ }^{11}$ Após o sucesso na comercialização da marca de café Max Havelaar, a gigante no setor de comercialização deste produto, Douwe Egberts, direciona parte de seus investimentos na comercialização de café orgânico.

12 No caso dos plantadores de café mexicanos, eliminar o atravessador (coyote) foi uma tarefa árdua para a cooperativa de produtores Max
Havelaar. Diversos tipos de violência e sabotagens foram enfrentados pelos produtores durante o processo de desenvolvimento da cooperativa.

$13 \mathrm{Na}$ medida em que a estratégia de vender os produtos justos e solidários em grandes hipermercados possibilita o acesso a todo o tipo de consumidor, ressalta-se que a expansão das grandes empresas de distribuição organizada, como por exemplo, Carrefour e Wal Mart, vem acarretando a diminuição dos postos de venda de alimentos causando o monopólio na comercialização de certos produtos e destruindo sistemas locais de distribuição. Na Itália, dos 413.000 postos de venda de alimentos existentes em 1981, restaram 200.000 em 1995. Vale lembrar também que a recente difusão de estabelecimentos caracterizados como negócios de hard discounts apresenta alternativas à monopolização da distribuição de alimentos pelos grandes estabelecimentos. Os lugares de hard discounts caracterizam-se por comercializar produtos de marcas pequenas e sem publicidade; os estabelecimentos não possuem trabalhadores que organizam o espaço de venda (gôndolas) e muito menos apresentam os produtos aos consumidores. O quadro de funcionários destes estabelecimentos resume-se em gerência e caixas. Também não existe investimento em publicidade por estes negócios, baixando os encargos financeiros e, conseqüentemente, os preços dos produtos comercializados. A rede Penny Market é um destes estabelecimentos espacializados por toda a Europa. Este tipo de comércio ganha cada vez mais consumidores e creio que se constituirá em um locus importante na comercialização dos produtos justos e solidários.

14 Outra característica que eleva o preço dos orgânicos é a necessidade da utilização de maiores contingentes de mão-de-obra. Estudos indicam que o agricultor utiliza um excedente de 30 a $50 \%$ de trabalhadores. No caso do agricultor familiar, ele é obrigado a dobrar a eficiência de seu trabalho ou contratar empregados.

15 Tradução realizada pelo autor.

16 O camponês José Bové ficou mundialmente conhecido quando organizou uma manifestação dos produtores franceses de queijo contra a 
redução dos subsídios e abertura do mercado europeu ocupando um Mac Donald's em uma cidadezinha no interior da França.

17 "Quando começa a surgir na Europa leis que regulam a plantação dos alimentos orgânicos, dos
450 mil hectares com este tipo de cultivo em 1992 passou-se para 4,5 milhões em 2001". (Revista Globo Rural, maio de 2004, p. 38).

18 Citada por Roozen e Hoff, 2002, p. 151.

\section{Bibliografia}

Fanfani, Roberto - L'agricoltura in Itália. Dalla riforma agrária alle colture biologiche. Bologna: il Mulino Editore, 1998

Fórmica, Carmelo - Geografia dell'Agricoltura. Roma: Ed. La Nuova Itália Scientifica, 2002.
Turri, Eugenio - La conoscenza del território. Venezia: Marsílio Editore, 2002.

Roozen, Nico; Hoff, Frans van der - Max Havelar. $L$ 'avventura del commercio equo e solidale. Milano: Ed. Feltrinelli, 2003. 
